\title{
Sigilo e confidencialidade na relação médico-paciente: conhecimento e opinião ética do estudante de medicina
}

Vitor Nagai Yamaki ${ }^{1}$, Renan Kleber Costa Teixeira ${ }^{2}$, João Paulo Santiago de Oliveira ${ }^{3}$, Edson Yuzur Yasojima ${ }^{4}$, José Antônio Cordero da Silva ${ }^{5}$

\section{Resumo}

Considerando-se que o segredo médico é característica moral obrigatória da medicina e pilar da relação médico-paciente, e o pensamento ético do médico o reflexo de sua formação acadêmica, viu-se a necessidade de pesquisar o conhecimento ético do estudante de medicina da Universidade do Estado do Pará. O estudo caracteriza-se pela aplicação de um questionário com situações onde os alunos deveriam julgar em quais o sigilo poderia ser quebrado. Foi ainda questionado se haviam lido o Código de Ética Médica ou o juramento de Hipócrates. Foram entrevistados 207 acadêmicos de medicina, do $1^{\circ}$ ao $4^{\circ}$ ano da Universidade do Estado do Pará. Foi observado que 25 estudantes apresentaram domínio sobre o sigilo médico, 135 possuíam conhecimento insatisfatório e 27 desconheciam o assunto. Assume importância fundamental a orientação ética dos alunos de medicina em busca da formação de egressos, capazes de cultuar, praticar e respeitar o sigilo do paciente.

Palavras-chave: Sigilo. Ética médica. Confidencialidade. Educação médica.

\section{Resumen}

El secreto y la confidencialidad de la relación médico-paciente: el conocimiento y la opinión ética del estudiante de medicina

Considerando que el secreto médico es una característica moral obligatoria de la medicina y el pilar de la relación médico-paciente y el pensamiento ético del médico, el reflejo de su formación académica, se vio la necesidad de investigar el conocimiento ético de los estudiantes de medicina de la Universidad del Estado de Pará. El estudio se caracteriza por un cuestionario con situaciones en las que el alumno debe juzgar en cuales la confidencialidad puede ser rota. También se preguntó si estos hubieran leído el Código de Ética Médica y el juramento de Hipócrates. Fueron entrevistados 207 estudiantes de medicina, del $1^{\mathrm{er}}$ a $4^{\circ}$ año de la Universidad del Estado de Pará, Brasil. Se observó que 25 estudiantes mostraron el dominio de la confidencialidad médica, 135 poseían pobre conocimiento y 27 mostraron desconocimiento del tema. Es de fundamental importancia la formación y la orientación ética de los estudiantes de medicina, para formar graduados capaces de rendir culto, practicar y respetar el sigilo del paciente.

Palabras-clave: Sigilo. Ética médica. Confidencialidad. Educación médica.

\begin{abstract}
Secrecy and cconfidentiality in the doctor-patient relationship: ethical knowledge and opinion of medical students

Given that the medical secrecy is a moral characteristic of medicine and basis of the doctor-patient relationship, and the physician's ethical thought reflect their academic background, it was necessary to research the ethical knowledge of medical students at the University of Para State. The study is characterized by a questionnaire with situations where the student should judge situations in which confidentiality could be broken. It was also asked whether they had read the Code of Medical Ethics and the Hippocratic Oath. 207 medical students were interviewed, from $1^{\text {st }}$ to $4^{\text {th }}$ year of University of the State of Para. It was observed that 25 students showed high-knowledge about medical confidentiality, with 135 as regular-knowledge and 27 showed low-knowledge about the issue. The ethical orientation to medical students becomes extremely important seeking to have graduates capable of practicing and respecting the patient confidentiality.

Key words: Secrecy. Medical ethics. Confidentiality. Medical education.
\end{abstract}

Aprovação CEP Uepa 34/11

1. Graduando vitoryamaki@gmail.com 2. Graduando renankleberc@hotmail.com 3. Graduando jpsoliveira91@hotmail.com 4. Doutor yasojima@globo.com 5. Doutorando corderobel4@gmail.com - Universidade do Estado do Pará (Uepa), Belém/PA, Brasil.

Correspondência

Vitor Nagai Yamaki - Rua Boa Ventura da Silva, 695, apt ${ }^{\circ} 1.104$ CEP 66055-090. Belém/PA, Brasil.

Declaram não haver conflito de interesse. 
O segredo médico sempre foi característica moral obrigatória da profissão médica e pilar da relação médico-paciente, sendo centralizado nas necessidades e direitos dos cidadãos à intimidade, passando a ser entendida como confidencialidade ${ }^{1}$. O dever de manutenção do sigilo médico decorre da necessidade do paciente confiar, irrestritamente, no profissional, com vistas a que possa ser estabelecida uma relação médico-paciente satisfatória, importante para que o tratamento transcorra da melhor forma possível, com a menor possibilidade de erros e iatrogenias ${ }^{2}$.

Os primeiros relatos de princípios éticos inerentes à profissão médica são atribuídos à Hipócrates quatro séculos antes da era cristã ${ }^{3}$. $O$ juramento de Hipócrates é até hoje referência para a conduta médica e contém preceitos éticos fundamentais à prática da medicina, como filantropia, não maleficência, justiça e confidencialidade ${ }^{4,5}$. Baseado nesses conceitos, o juramento representa, não só para os médicos, mas principalmente para a sociedade, um fator que corrobora o compromisso com os princípios éticos vigentes ${ }^{6}$.

Infelizmente, não basta o ser humano conhecer o que é certo e errado para adotar a melhor conduta, faz-se preciso haver limites e punições estabelecidos na regulamentação profissional ${ }^{7}$. Nesse contexto, o Conselho Federal de Medicina elaborou o Código de Ética Médica (CEM), no qual normas fundamentais específicas disciplinam integral e isoladamente o exercício da medicina; as relações entre médicos, entre médico e paciente; e entre médico e instituição de saúde ou estado ${ }^{\text {. }}$.

Diversos documentos reafirmam a importância de preservar esses princípios éticos: o CEM, no Capítulo IX, a Constituição Federal ${ }^{9}$, no artigo $5^{\circ}$, e os códigos penal ${ }^{10}$ e civil ${ }^{11}$ defendem o sigilo médico como um direito de todo paciente, sendo fundamental sua observação para a garantia do princípio da autonomia, definido no próprio juramento hipocrático: Tudo aquilo que tenha ou não relação com a prática da minha profissão, ver ou ouvir da vida dos homens que não deva ser divulgado, não divulgarei, respeitando tudo aquilo que deva ficar em segredo ${ }^{3}$.

Para responder a esses imperativos, a formação ética e humanística dos estudantes de medicina vem sendo bastante valorizada e questionada na atualidade. No entanto, o ensino da ética nas escolas de medicina do Brasil caracteriza-se, ainda, pela visão marcadamente deontológica, necessária, mas não suficiente para atender às necessidades de formação do profissional. O modelo clássico de ensino da ética por meio das disciplinas de medicina legal e deontologia se tornou insuficiente para atender à formação humanista imprescindível ao médico, vez que perderam a capacidade de responder aos dilemas morais apresentados pelos avanços das ciências, em especial pelas novas tecnologias aplicadas à biomedicina ${ }^{12}$.

Se a escola médica, como instituição formadora, tem a obrigação de zelar pela formação ética dos seus futuros médicos, é importante a inserção dos preceitos éticos e bioéticos precocemente no curso, bem como sua manutenção durante toda a graduação. Essa tarefa deve envolver todos os docentes e não somente os professores de ética médica, pois cada um deles precisa trabalhar o conteúdo específico de sua disciplina de maneira a contemplar a percepção e as discussões em torno das orientações, preceitos e princípios éticos atinentes à formação profissional. Só assim poder-se-á reforçar uma atitude social e tornar o aluno atento ao comportamento ético da profissão ?

Portanto, o médico, ao exercer sua profissão, deve em obediência aos princípios éticos norteadores de sua atividade, zelar e trabalhar pelo perfeito desempenho da medicina e pelo prestígio e bom conceito da profissão ${ }^{2}$. Daí a importância da noção ética desde os primeiros anos e ao longo da graduação médica, pois o conhecimento solidificado no decorrer da formação é essencial à prática profissional futura ${ }^{1}$. Considerando a importância desses pressupostos para a correta formação discente, este trabaIho visa avaliar o conhecimento e a opinião ética dos estudantes de medicina da Universidade do Estado do Pará, baseado no princípio do sigilo médico.

\section{Método}

O estudo caracteriza-se como prospectivo e transversal, aplicado em uma casuística de 207 acadêmicos de medicina, do $1^{\circ}$ ao $4^{\circ}$ ano da Uepa, de um total de 407 alunos regularmente matriculados. Dos 207 estudantes de medicina entrevistados, matriculados entre o $1^{\circ} \mathrm{e} \mathrm{o} 4^{\circ}$ ano, 20 protocolos foram descartados por preenchimento indevido $(9,7 \%)$. Assim, o estudo contou efetivamente com 187 protocolos, cujo preenchimento revelou-se apropriado.

Nestes 187 protocolos que compuseram as bases analíticas do estudo foi encontrada a seguinte distribuição: $48(25,66 \%)$ referentes aos estudantes do $1^{\circ}$ ano; 43 (22,99\%) aos do $2^{\circ}$ ano; 47 (25,13\%) aos do $3^{\circ}$ ano e $49(26,20 \%)$ aos do $4^{\circ}$ ano. Foram incluídos todos os discentes do $1^{\circ}$ ao $4^{\circ}$ ano do curso de medicina, regularmente matriculados, de ambos 
os sexos e de qualquer idade. Além dos instrumentos preenchidos erradamente foram também excluídos do estudo os alunos que já cursaram outro curso da área da saúde e aqueles que não aceitaram participar da pesquisa ou não assinaram o TCLE.

No protocolo de pesquisa aplicado havia 12 opções de situações do cotidiano para as quais os alunos deveriam julgar em quais o sigilo médico poderia ser quebrado. Apenas em duas poderia haver a revelação do segredo médico (Anexo 1). Também foi questionado se haviam lido o CEM ou se tinham algum conhecimento sobre o juramento de Hipócrates. Além disso, foi registrado o ano da faculdade em que estavam matriculados, se receberam orientação sobre sigilo médico, se comentavam casos vivenciados nas práticas e sua opinião sobre o tema. É importante ressaltar que, na Uepa, a disciplina de deontologia médica e direitos humanos é ministrada no $2^{\circ}$ ano do curso de medicina.

Para avaliar os resultados foi adotado o seguinte critério: os acadêmicos que marcaram apenas as duas alternativas viáveis obtiveram um aproveitamento total, foram considerados no grupo de conhecimento adequado; por sua vez, os que não assinalaram nenhuma das duas alternativas corretas foram enquadrados no grupo de desconhecimento sobre o segredo médico; os que estavam em situação intermediária, ou seja, aqueles que marcaram apenas uma correta, uma correta e uma falsa ou as duas corretas e uma ou mais falsas, foram enquadrados no grupo de conhecimento insatisfatório.

O protocolo de pesquisa utilizado foi validado por meio de um teste piloto utilizando 23 discentes do $5^{\circ}$ e $6^{\circ}$ ano de medicina - cujos resultados não foram utilizados nos achados finais do estudo. Foi utilizado o teste de contingência em C para compa- rar o grau de conhecimento com as demais variáveis estudadas. Foi adotado como índice de significância $p<0,05$.

\section{Resultados}

O desempenho dos estudantes no preenchimento do protocolo do estudo foi representado por 25 $(13,36 \%)$ deles enquadrados no grupo de domínio do conhecimento; 135 (72,19\%) incluídos no grupo de conhecimento insatisfatório e $27(14,45 \%)$ sem nenhum acerto, pertencentes ao grupo de desconhecimento do assunto. Na Tabela 1 encontra-se a distribuição do grau de conhecimento ético relacionado ao ano da faculdade. Cabe ressaltar, entretanto, que não se observou qualquer resultado estatisticamente significante, tendo os estudantes do $1^{\circ}$ ao $4^{\circ}$ ano apresentado o mesmo grau de conhecimento sobre o sigilo médico.

Encontrou-se, todavia, diferença estatística entre o grau de conhecimento dos discentes que haviam lido o CEM $(p<0,05)$ ou o juramento de Hipócrates $(p<0,05)$, identificando-se que aqueles que leram um dos dois apresentaram maior conhecimento quando comparados aos que não tiveram acesso a tais documentos.

Avaliando a atitude ética dos estudantes a respeito do segredo médico, $164(87,7 \%)$ dos entrevistados alegaram fazer comentários a respeito dos pacientes atendidos em estágios extracurriculares e disciplinas da faculdade. Dentre estes, 118 (71,95\%) julgam sua atitude de quebra do sigilo médico como eticamente aceitável. Quando questionados se, durante os atendimentos, alguma orientação a respeito do sigilo médico havia sido repassada, somente 70 estudantes $(37,4 \%)$ informaram ter recebido esse tipo de direcionamento ético.

Tabela 1. Distribuição do grau de conhecimento acerca do sigilo médico, segundo o ano do curso

\begin{tabular}{|c|c|c|c|c|c|c|}
\hline $\begin{array}{l}\text { Ano do } \\
\text { curso }\end{array}$ & $\begin{array}{l}\text { Conhecimento } \\
\text { adequado }\end{array}$ & $\%$ & Intermediário & $\%$ & Desconhecimento & $\%$ \\
\hline $1^{\circ}$ ano & 4 & 16,00 & 33 & 24,44 & 11 & 40,74 \\
\hline $2^{\circ}$ ano & 8 & 32,00 & 27 & 20,00 & 8 & 29,62 \\
\hline $3^{\circ}$ ano & 8 & 32,00 & 34 & 25,19 & 5 & 18,51 \\
\hline $4^{\circ}$ ano & 5 & 20,00 & 41 & 30,37 & 3 & 11,11 \\
\hline Total & 25 & 100,00 & 135 & 100,00 & 27 & 100,00 \\
\hline
\end{tabular}

Fonte: protocolo de pesquisa. $p=0,1310$ (contingência em C).

\section{Discussão}

A garantia do sigilo médico é um dos pontos chaves para o desenvolvimento da relação médico- paciente. Este princípio ético é fundamental para garantir a veracidade da narrativa e impedir que fatos não sejam ocultados ${ }^{13,14}$. Contudo, em algumas situações há necessidade de quebra dessa 
confidencialidade, principalmente quando o fato possa causar dano ou morte do paciente - em tal circunstância o paciente deve ser anteriormente informado, com justificativa, acerca dos motivos dessa atitude ${ }^{15-17 .}$ O conhecimento das situações onde o sigilo pode ser quebrado é de vital importância, devendo ser construído desde a formação básica do estudante de medicina.

Outro ponto chave para a manutenção da confidencialidade dos dados do paciente refere-se à limitação de pessoas com acesso aos prontuários. Em 1982, Siegler ${ }^{14}$ relatou que uma paciente submetida à colecistectomia teve seus dados expostos a mais de 100 profissionais de saúde e estudantes, que detiveram acesso a informações desnecessárias à realização de suas funções, promovendo assim a quebra da confidencialidade ${ }^{16,18}$.

Em relação aos estudantes, quando não estiverem diretamente ligados ao processo de saúdedoença do paciente não deveriam ser informados sobre dados deste ${ }^{14,17,18}$, como, por exemplo, estudantes que frequentam enfermarias com a finalidade de aprender sinais e sintomas não deveriam ter informações pessoais dos pacientes. Contudo, ao participarem diretamente do processo saúde-doença, sempre sob a tutela de um supervisor, há justificativa plausível para conhecer os dados do paciente, mas a manutenção do sigilo é requisito essencial aos futuros profissionais ${ }^{18}$.

Neste estudo pôde-se evidenciar que grande parte dos alunos da Uepa não domina o assunto sobre sigilo e confidencialidade médica, como constatado em muitas outras escolas médicas no país ${ }^{19}$. 0 ensino da ética nas faculdades de medicina do Brasil apresenta-se, ainda, marcadamente deontológico e pontual ${ }^{20,21}$, havendo necessidade de que venha a ser ensinada continuamente, desde as matérias básicas e durante as disciplinas clínicas, com vistas a garantir que os discentes a assimilem.

Estima-se que alunos mais avançados no curso estão mais instruídos no ponto de vista do segredo médico, vez que cursaram maior número de disciplinas e tiveram contato com maior quantidade de pacientes, adquirindo maior acervo à formação médica ${ }^{22,23}$ - contudo, neste estudo não houve diferença do grau de conhecimento em relação ao ano do curso. Adicionalmente, distinguem duas formas de ética - que se complementam - na formação do indivíduo: a ética moralista e a ética espontânea ${ }^{3,24}$. A moralista concerne aos preceitos adquiridos, informações exógenas que são internalizadas no indivíduo a partir de experiências vivenciadas, dentre as quais o próprio curso de medicina; a espontânea, por sua vez, surge como algo natural, sem relação com o conhecimento adquirido.

Neste estudo percebeu-se que o ano de graduação não influenciou o conhecimento dos discentes. Assim, presume-se que o conhecimento dos mesmos foi baseado numa ética espontânea, não sendo influenciado pelas experiências adquiridas. Então, pode-se presumir que no decorrer de sua prática houve poucas discussões sobre a importância do sigilo médico. Tal ilação pode ser fundamental no fato de que a maioria dos entrevistados acredita ser eticamente aceitável comentar os casos vivenciados durante as atividades práticas.

A quebra da confidencialidade por parte dos estudantes da área da saúde foi verificado por outros estudos ${ }^{25-28}$, nos quais se percebe que apresentam maior tendência a desrespeitar esse principio em relação aos profissionais, havendo vários motivos que colaboram para tal realidade, como a impossibilidade de os discentes serem punidos pelos conselhos de suas sociedades e acreditarem ser correto relatar a amigos casos vivenciados nas práticas como meio de compartilhar a experiência.

O conteúdo curricular não vem se mostrando decisivo no processo de transmissão do conhecimento ético para os estudantes. Poder-se-ia argumentar, inclusive, que para que os estudantes assimilem a reflexão ética em sua prática profissional é importante que se desenvolvam, concomitantemente com as matérias já consolidadas, metodologias de aprendizagem que privilegiem o reconhecimento, na prática, de situações eticamente conflituosas. Além disso, é fundamental que ambas as modalidades de transmissão de conteúdo sejam introduzidas mais precocemente no currículo, de forma gradativa e bem distribuída no decorrer da graduação ${ }^{29,30}$.

Os graduandos que relataram ter lido o CEM ou o juramento de Hipócrates apresentaram maior conhecimento que os demais discentes, concordando com os estudos de Bittencourt ${ }^{4}$ e Almeida ${ }^{31}$ que demonstraram que quanto maior a frequência na leitura do CEM, maior o conhecimento sobre preceitos éticos, revelando que o conhecimento sobre as normas específicas que disciplinam, integral e isoladamente, o exercício da medicina confere maior autoridade e discernimento ao futuro profissional.

O CEM representa um código moral que serve como modelo de conduta a ser seguido pelos médicos, mas não é um modelo para os profissionais médicos já graduados, não correspondendo à realidade dos discentes, mesmo apresentando papel ímpar na formação médica ${ }^{32,33}$. Uma alternativa a esse 
quadro de indefinição baseia-se na implantação de códigos de ética do estudante de medicina, que ao apresentarem um caráter educativo também auxiliariam na formação ética dos graduandos ${ }^{33}$.

O fundamento das bases éticas da medicina tradicional foi baseado no juramento de Hipócrates e nos livros deontológicos e normativos da área. No juramento, havia o compromisso de o médico usar a medicina em benefício dos pacientes; de conservar em segredo os conhecimentos médicos, exceto para seus pares; não manter relações sexuais com os pacientes e não administrar substâncias que poderiam levar à morte ou provocar efeitos danosos. Por ser um juramento que enfatiza as condutas éticas que o médico deveria realizar, transformou-se, ao longo da história, em importante parâmetro para os médicos avaliarem suas práticas ${ }^{34}$.

A natureza dos preceitos éticos contida nesse juramento continua atual, servindo como ponto de referência também para os discentes compreenderem melhor a profissão médica. Contudo, bem como o Código de Ética Médica, não apresenta mecanismo para limitar condutas equivocadas dos discentes, o que indica, novamente, a importância de um código de ética do estudante de medicina, que deve incluir as diretrizes fundamentais tanto do juramento de Hipócrates quanto do Código de Ética Médica.

\section{Considerações finais}

A partir do estudo descrito e analisado neste trabalho se assume a importância fundamental da orientação ética, teórica e prática para a formação dos discentes ao longo do curso de medicina. Acredita-se que a formação pautada em valores humanísticos e éticos em muito contribuirá para fomentar o respeito ao princípio milenar do segredo médico, que é o alicerce primordial na boa relação médico-paciente. Ao permitir e incentivar os futuros profissionais desde a graduação para que desenvolvam a sensibilidade para com o outro, se estará também fortalecendo sua capacidade para detectar problemas e desvios à conduta ética, de forma que venham a praticar sua profissão baseando-se em condutas éticas e morais aplicadas para o bem de seus pacientes e da sociedade.

\section{Referências}

1. Gracia D. La confidencialidad de los datos genéticos. Ética de los confines de la vida. Bogotá: El Buho; 1998. p. 137-50. (Ética y vida: estudios de bioética, v. 3)

2. Krogh E, Brito LMO, da Silva DSM, Ferreira ECMF, da Silva RA. Consulta ginecológica na adolescência: aspectos relacionados e motivações determinantes para sua realização. Rev Pesq Saúde. 2012;13(2):11-6.

3. Mendonça AC, Villar HCCE, Tsuji SR. O conhecimento dos estudantes da faculdade de medicina de Marília (Famema) sobre responsabilidade profissional e segredo médico. Rev Bras Educ Méd. 2009;33(2):221-9.

4. Beiner M, Lannotti GC. O paternalismo e o juramento hipocrático. Rev Bras Saúde Matern Infant. 2010;10(2 Suppl):s383-9.

5. Wanssa MCD. Autonomia versus beneficência. Rev. bioét. (Impr.). 2011;19(1):105-17.

6. Bitencourt AGV, Neves FBCS, Kuwano AY, Rebello GS, Fraga AN, Neves NMBC. Reflexões sobre os juramentos utilizados nas faculdades médicas do Brasil. Rev Bras Educ Méd. 2007;31(1):31-7.

7. Lemos K, Neves N, Athanazio R, Lordelo M, Bitencourt A, Neves FS et al. Proposta de código de ética dos estudantes de medicina da Bahia. Gaz Méd Bahia. 2005;75(2):133-42.

8. Conselho Federal de Medicina. Código de Ética Médica: resolução CFM n 1.246/1988. Brasília: CFM; 1998.

9. Brasil. Constituição da República Federativa do Brasil, 1988. [Internet]. (acesso 18 maio 2013). Disponível: http://www.planalto.gov.br/ccivil_03/constituicao/constituicao.htm

10. Brasil. Decreto-lei $n^{\circ} 2.848$, de 7 de dezembro de 1940. Código Penal. [Internet]. (acesso 18 maio 2013). Disponível: http://www.planalto.gov.br/ccivil_03/decreto-lei/del2848compilado.htm

11. Brasil. Lei $n^{\circ} 10.406$, de 10 de janeiro de 2002. Código Civil. [Internet]. (acesso 18 maio 2013). Disponível: http://www.planalto.gov.br/ccivil_03/leis/2002//10406.htm

12. Siqueira J, Sakai M, Eisele R. $O$ ensino da ética no curso de medicina: a experiência da Universidade Estadual de Londrina (UEL). Bioética. 2002;10(1):85-95.

13. Teixeira RKC, Silva JAC. Autonomia e beneficência em um CEP universitário. Revista da AMRIGS. 2012;56(3):220-4.

14. Siegler M. Confidentiality in medicine: a decrepit concept. N Engl J Med. 1982;307(24):1.518-21.

15. Santos MFO, Santos TEO, Santos ALO. A confidencialidade médica na relação com o paciente adolescente: uma visão teórica. Rev. bioét. (Impr.). 2012;20(2):318-25.

16. Niveau G, Burkhardt S, Chiesa S. Medical confidentiality and the competent patient. J Med Ethics. 2013;39(11):686-9. 
17. Macara AW. Confidentiality: a decrepit concept? Discussion paper. J R Soc Med. 1984;77(7):577-84.

18. Anesi GL. The "decrepit concept" of confidentiality, 30 years later. Virtual Mentor. 2012;14(9):708-11.

19. Ferreira RC, Silva RF, Zanolli MB, Varga CRR. Relações éticas na atenção básica em saúde: a vivência dos estudantes de medicina. Ciênc Saúde Coletiva. 2009;14 (1 Suppl):1.533-40.

20. Amorim KPC, Araujo EM. Formação ética e humana no curso de medicina da UFRN: uma análise crítica. Rev Bras Educ Méd. 2013;37(1):138-48.

21. Nunoz D, Munoz DR. O ensino da ética nas faculdades de medicina do Brasil. Rev Bras Educ Méd. 2003;27(2):114-24.

22. Hossne WS, Hossne RS. Opinião do estudante de medicina sobre algumas questões bioéticas. Bioética. 1998;6(2):127-33.

23. Fard NN, Asghari F, Mirzazadeh A. Ethical issues confronted by medical students during clinical rotations. Med Educ. 2010;44(7):723-30.

24. Weil PG. A nova ética. Rio de Janeiro: Record; 2002.

25. Lees AB, Godbold R. To tell or not to tell? Physiotherapy students' responses to breaking patient confidentiality. New Zealand Journal of Physiotherapy. 2012;40(2):59-63.

26. Sales-Peres SHC, Sales-Peres A, Fantini AM, Freitas FDR, Silva OP, Chaguri RH. Sigilo profissional e valores éticos. RFO. 2008;13(1):7-13.

27. Loch JA, Clotet J, Goldim JR. Privacidade e confidencialidade na assistência à saúde do adolescente: percepções e comportamentos de um grupo de 711 universitários. Rev Assoc Med Bras. 2007;53(3):240-6.

28. Beauchamp TL, Childress JF. Princípios de ética biomédica. São Paulo: Loyola; 2002.

29. Patenaude J, Niyonsenga T, Fafard D. Changes in students' moral development during medical school: a cohort study. CMAJ. 2003;168(7):840-4.

30. Lind G. Moral regression in medical students and their learning environment. Rev Bras Educ Méd. 2000;24(3):24-33.

31. Almeida AM, Bitencourt AGV, Neves NMBC, Neves FBCS, Lordelo MR, Lemos KM et al. Conhecimento e interesse em ética médica e bioética na graduação médica. Rev Bras Educ Méd. 2008;32(4):437-44.

32. Neves NMBC, Siqueira JE. A bioética no atual Código de Ética. Rev. bioét. (Impr.). 2010;18(2):439-50

33. Ract ALP, Maia JA. Reflexão sobre quatro versões do código de ética do estudante de medicina. Rev. bioét. (Impr.). 2012;20(3):502-6.

34. Almeida JLT, Schramm FR. Paradigm shift, metamorphosis of medical ethics, and the rise of bioethics. Cad. Saúde Pública. 1999;15 (1 Suppl.):15-25.

\section{Participação dos autores}

Todos os autores participaram da elaboração, correção gramatical e revisão do artigo. Vitor Nagai Yamaki participou da coleta de dados e escrita inicial do artigo; Renan Kleber Costa Teixeira realizou a coleta de dados e análise estatística; João Paulo Santiago de Oliveira participou da coleta de dados e formatação inicial do artigo; Edson Yuzur Yasojima e José Antônio Cordero da Silva orientaram todas as etapas da pesquisa, realizando a revisão crítica do trabalho, bem como deste artigo.

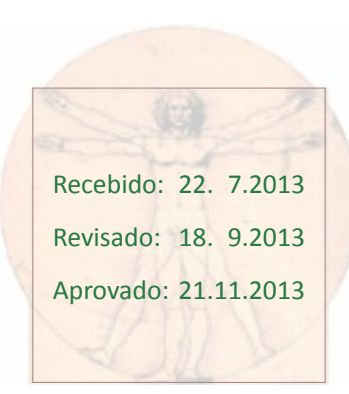

